\title{
Economic impact of an outbreak of Foot and Mouth Disease in Khartoum State, Sudan
}

\author{
A M El-Hussein ${ }^{1 *}$ and A Daboura ${ }^{2 *}$ \\ 1. Central Veterinary Research Laboratories, P. O. Box 8067, Al Amarat, Khartoum, Sudan. \\ 2. Animal Health Administration, Eddamer, River Nile, State. \# Deceased \\ * Corresponding author email: abdelhussein@hotmail.com \\ Received: 07-10-2011, Accepted: 15-11-2011, Published Online: 12-01-2012 \\ doi: $10.5455 /$ vetworld.2012.219-222
}

\begin{abstract}
The economic impact of an outbreak of foot and mouth disease that took place during 2002 was assessed in dairy farms of Khartoum state, Sudan. A total of 11 farms ( 8 cooperative and 3 privately owned) of mostly crossbred Friesian $\mathrm{X}$ indigenous cattle were investigated. The total number of the animals in these farms were 1160 of which 715 were adult and 445 were calves. The statistical analysis was carried out using $t$ student test. The costs of the outbreak were assessed in terms of losses in milk production, costs of drugs used to alleviate the symptoms, and death of affected animals. The overall cost to the dairy farmers in the state was estimated USD 1771924 with the loss in milk production constituting the main component in this cost.

Key Words: Economic impact; Diary cattle; FMD; Sudan
\end{abstract}

\section{To cite this article :}

El-Hussein AM and Daboura A (2012) Economic impact of an outbreak of Foot and Mouth Disease in Khartoum State, Sudan, Vet. World. 5(3):219-222, doi: 10.5455/vetworld.2012.219-222.

\section{Introduction}

Foot and Mouth Disease (FMD) is the most contagious of animal diseases with a great potential for causing heavy economic losses in susceptible livestock. The disease is characterized by high morbidity, low mortality, and development of vesicles and erosions in the mucosa of the mouth and skin of the inter-digital spaces and coronary bands. Cloven-hoofed animals such as cattle, sheep, goats, camels and pigs as well as several wild animals are susceptible to infection with FMD.

Countries free of FMD take every possible measure to prevent entry of virus. An FMD outbreak in these countries may cause substantial costs in term of costs of control, disruption in animal movement, prevention measures and prohibition by countries free of disease of the importation or exportation of agricultural products. Farmers affected by presence of FMD suffer severe economic losses due to application of quarantine measures, production losses resulting from reduction in milk yield, milk or livestock that cannot be marketed, mastitis, weight loss and lameness in draught animals. In countries not free of FMD the disease can also cause great financial losses in terms of production losses as mentioned above and costs of control through vaccination programs.
Regular, almost annual outbreaks of FMD are reported in Northern Sudan (Eisa and Rweyemamu, 1979; El Ghali and El Hussein, 1995). Earlier studies indicated that the country is highly endemic for FMD (Abu Elzein, 1983,Abu Elzein et al,1987) and four of the seven FMD virus serotypes (O, A, SAT- 1 and SAT2) have been reported (Abu Elzein, 1987). More recently, Habiela et al (2010) indicated that three serotypes (O, A, and SAT2) were detected in 24 samples that were collected from Sudan during the period 2004-2008. These authors concluded that the recent outbreaks of FMD in Sudan were caused by seotypes $\mathrm{O}$ and SAT2, while serotype A was last detected in 2006 (Habiela et al 2010). Inspite of these facts, little if any attention has been paid to assess the economic importance of FMD in the Sudan.

The aim of this communication is to shed some lights on the economic aspects of an FMD outbreak that recently took place in dairy farms in Khartoum State.

\section{Materials and Methods}

Epizotiologic data concerning the year 2002 FMD outbreak were collected in several cooperative and private dairy farms in Hillat Kuku area in Khartoum North. Animal owners and veterinarians 
Economic impact of an outbreak of Foot and Mouth Disease in Khartoum State, Sudan

Table-1: Incidence of FMD in dairy farms in Hillat Kuku, Khartoum North

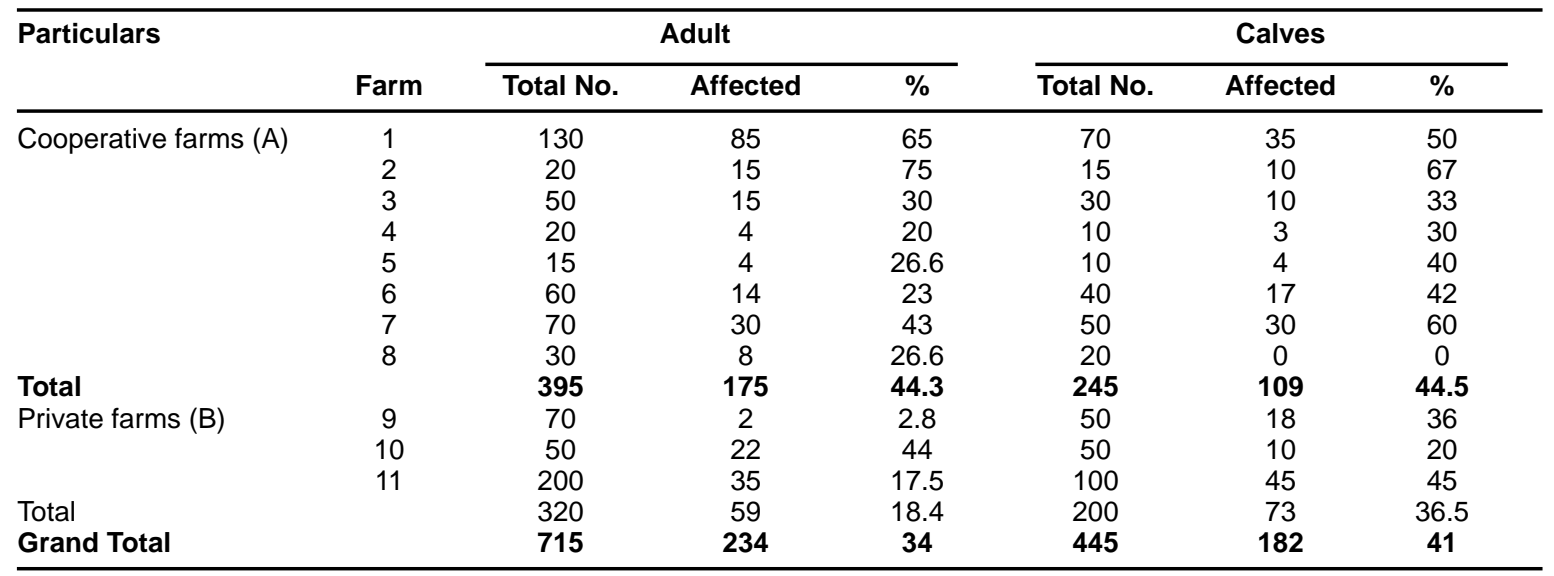

employed by these farms were questioned on several occasions during the course of the outbreak on aspects of the disease including incidence of FMD, losses in milk production due to the disease and its clinical manifestation (e.g. lameness, mastitis, ulcerations on teats of lactating animals and deaths due to the disease).

A total of 11 farms ( 8 cooperative and 3 privately owned) of mostly crossbred Friesian $\mathrm{X}$ indigenous cattle were investigated. The total number of the animals in these farms was 1160 of which 715 were adult and 445 were calves. The statistical analysis was carried out using $t$ student test.

\section{Results}

I. Epizootiological investigations: The first occurrence of the disease was reported by owners to take place in late December 2002 and to have spread to all farms in the area by early February 2003.The disease was diagnosed as FMD based on clinical findings and symptoms The owners claimed that FMD is an annual event on their premises and none of them reported using vaccines against the disease.

The incidence of FMD in the investigated farms is shown in tables ( 1 and 2 ). The incidence was higher, but not significantly different $(\mathrm{P}>0.05)$ in total number of calves (41\%) compared to adults (34\%) in both kinds of farms. However, there was a significant difference
$(\mathrm{P}<0.05)$ in adults affected in the co-operative farms $(44.3 \%)$ compared to adults in the privately owned one $(18.4 \%)$. The highest reported incidence was $71 \%$ in one cooperative farm and the lowest was $16 \%$ in a cooperative farm also. The main longer-term clinical side effects observed were lameness, mastitis and teat ulcerations with incidences of 50\%, $0.6 \%$ and $41 \%$ respectively. Deaths due to FMD infection numbered $19(5.7 \%)$ (Table 3).

II. Estimation of economic costs due to FMD outbreak: The costs reported herein were estimated in Sudanese Dinars (the Sudanese currency used during the time of the outbreak) and then converted to US dollars using change rates of that time.

1. Cost due to loss in milk production: It is estimated that there are around 400,000 crossbred animals in dairy farms around urban areas of Khartoum State. Most of the farms keep only negligible number of bulls. As shown here adult females represented $62 \%$ of the total number kept in the farms (Table-2). Hence the total number of crossbred adult females assuming $60 \%$ females (Gameel et al., 1987) is 244,000 and total number of producing cows assuming $50 \%$ lactating cows is 122,000 . Number FMD infected lactating cow assuming FMD incidence of $38 \%$ (table 2) is 46300.

As most of the animal owners estimated a $50 \%$

Table-2: I ncidence of FMD disease in cooperative farms (group A) and private farms (group B) in Khartoum State

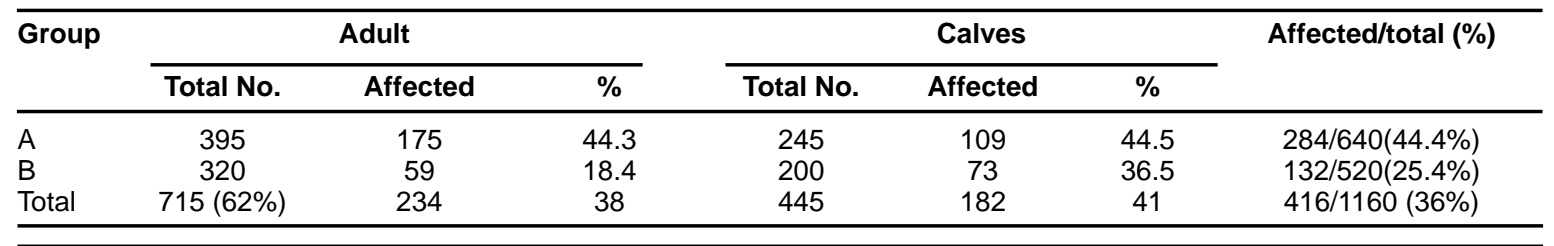


Economic impact of an outbreak of Foot and Mouth Disease in Khartoum State, Sudan

Table-3: I ncidence of some clinical sequelae of FMD

\begin{tabular}{cccccc}
\hline Farm Number & $\begin{array}{c}\text { Total number of } \\
\text { animal affected }\end{array}$ & Death (\%)* & Lameness (\%) & Mastitis (\%) & Teat ulceration(\%) \\
\hline 1 & 120 & $5(4)$ & $120(100)$ & - & $120(100)$ \\
2 & 25 & $10(40)$ & $N$ & $N$ & 5 \\
3 & 25 & - & $7(28)$ & $2(8)$ & - \\
4 & 7 & - & $2(29)$ & - & $1(13)$ \\
5 & 8 & - & $8(26)$ & - & $1(3)$ \\
6 & 31 & - & $8(13)$ & - & - \\
7 & 60 & - & - & - & - \\
8 & 8 & - & - & - & $1(3)$ \\
9 & 20 & $4(12.5)$ & $9(28)$ & $2(0.6)$ & $129(41)$ \\
10 & 32 & $19(5.7)$ & $156(50)$ & & \\
\hline
\end{tabular}

*(\%) incidence, $\mathrm{N}$ : not available

reduction in the milk yield that lasted for at least two weeks and the average yield of a crossbred cow under Sudan conditions is estimated at $22 \mathrm{Ibs} /$ day (Mohammadin, 1994). Hence total loss in milk production over two weeks period is 7,130,200 Ibs.

Total cost of the lost milk assuming 50 dinnars/Ib (which is the lowest price) is $356,510,000$ Dinnars or 1,340,263 USD.

2. Cost due to veterinary drugs used to alleviate the effects of FMD: The cost of systemic antibiotic treatment, use of multivitamins and antiseptics for dressing of infected wounds is estimated by owners to range between 700 and $2500 \mathrm{SD} /$ animal (average 1340 SD). Hence total cost of treatment assuming $1340 \mathrm{SD} / \mathrm{animal}$ is $62,042,000 \mathrm{SD}$ or $233,240,6 \mathrm{U \$}$.

3. Cost due to death of affected animals: As shown in table (3), 5.7\% of the affected animals may die due to complications of FMD. Most of the dead animals are calves. Then the total number of deaths due to FMD is 2639. Total cost due to death assuming $20,000 \mathrm{SD} /$ animal is $52,780,000 \mathrm{SD}$ or $198,420 \mathrm{USD}$.

4. Overall cost of the FMD outbreak: The total cost of the FMD outbreak including costs due to milk production loss, drugs used, and death sums up to $471,332,000$ SD or $1,771,924$ USD.

\section{Discussion}

FMD in Sudan is still ignored because of the need of the veterinary authorities, and justifiably so, to deal with more pressing disease problems such as PPR, sheep and goat pox, Contagious Bovine Pleuro Pneumonia, Haemorrhagic septicaemia etc, which cause higher mortalities and severe economic losses. The successes that have been achieved over the past two decades in the control of these conditions should, however, create some room for other diseases to be attended to. In this respect, FMD should come into prominence as it is considered one of the major impediments to our livestock and livestock products export. Hence, studies such as the one presented here are badly required to help clarify such alleged importance by identifying major health and production problems and their relative importance. They are also required to set priorities and develop policies and to support implementation of disease control programs.

The epizootiological findings on FMD reported here in were mainly meant to serve as guiding parameters in the assessment of the economic impact of FMD on the dairy industry in Khartoum State. However, it may be worthwhile to briefly discuss few of these findings. This study showed that the incidence of FMD varied greatly between farms. This may relate to management practices, as the incidences were substantially higher in cooperative farms than in privately managed farms. Cooperative farms premises are poorly maintained with poor fences allowing for free movement of both animals and personnel among these farms. This variation in incidence also indicated none or partially immune animal populations. This is also with the claim by the livestock owners and veterinarians in the area "that FMD is an annual event on their premises" may indicate frequent introduction of new types and/or subtypes of FMD virus. This study also reveals that no measures e.g. isolation of infected animals, restriction of movement. etc. are undertaken to control spread of FMD, to the contrary, some owners deliberately infect their animals by allowing health animals to mix with affected ones or alternatively by rubbing collected vesicles materials from FMD affected animals to the mouth of healthy animals.

The findings in the present investigation indicated that losses due to reduced milk production constituted the main $(75.6 \%)$ component in the economic impact 
followed by costs due to mortalities $(13.2 \%)$, and costs of drugs used (11.2\%). This finding could highlight the effect of FMD not only from economical point of view, but also the effect on food security and livelihood of the small holder farmers as milk constitutes a major item in the food of these people in Sudan.

Although, the economic costs of FMD outbreak in Khartoum State $(471,332,000$ SD or $1,771,924$ U\$) presented here were lower than that estimated (4-6 million USD) for tropical theileriosis in the same area (Latif, 1994), they still represent substantial losses. They are even so for the smallholders, which is the case of the majority of animal owners in the area. Furthermore, there are some hidden costs that were hard to gauge. These include lost and reduced rates of body weight gain, reduction in milk yield and increased culling due to heat intolerance syndrome (characterized by unthriftiness), permanent lameness or mastitis with complete loss of one or more udder quarters due to mastitis. Furthermore, FMD costs to the national economy can be even greater due to reduced access to existing markets access and inability to open new markets, importation of powdered milk to meet an ever increasing demand for dairy products, and costs of (if embarked upon) research and control programs.

Finally, the main tool to control FMD in a highly endemic area like Sudan is the use of highly potent vaccines. The estimated cost of these vaccines, which have to be imported, is around $700 \mathrm{SD} /$ animal (USD 2.6) which would not be cost effective when taking into consideration that an animal has to be vaccinated at least twice before effective protection could be attained. Obviously, these vaccines have to be produced locally in Sudan in order to reduce cost and to swiftly switch to and adopt new vaccine strains as they arise in the field. In addition, local FMD vaccine production could induce responsible authorities to opt for country wide vaccination programs as had occurred with other diseases of economic importance in the Sudan.

\section{Acknowledgements}

The authors wish to thank animal owners, veterinarians, and laborers in the dairy farms visited during the outbreak. We would also like to thank Dr. Diaeldin A. Salih for statistical analysis and the Director General of the Animal Resources Corporation (ARRC) for permission to publish this work.

\section{Conflict of interest} interest.

Authors declare that they have no conflict of

\section{References}

1. AbuElZein,E.M.E.(1983).Foot and mouth disease in the Sudan. Rev. Tech. Off. Int. Epiz. 2: 177-188.

2. AbuElZein, E.M.E., Newman, J, Grow the r, J.E., Barret I.T., and McGrane,J.J. (1987). The prevalence of antibodies against foot and mouth disease in various species of Sudanese livestock following natural infection.Rev.Elev.Med.vet.Pays.trop. 40:7-12.

3. Eisa,M. and Rweyemamu,M.M.(1979). A note on the epizootiology of foot and mouth disease in the Sudan.Bull.Anim.Hlth.Prod.Afr.25:108-115.

4. El Ghali A., and El Hussein, A.M. (1995). Diseases of Livestock in Edamer Province: A two years retrospective study. Sud. J. Vet. Sci. \& Ani. Husb. 34: $37-45$.

5. Gameel, S.A.M., Idris,A, and.El Wali,A. (1987). Economic importance of brucellosis in the Sudan. Harbi et al (eds). Symposium on animal brucellosis in the Sudan, 15-16 September1987.pp 61-64.

6. Habiela, M., Ferris, N.P., Hutchings, G.H., Wadsworth, J., Reid, S.M., Madi, M., Ebert K. Sumpton, K.J., Knowels N.J., King, D.P., and Paton, D.J. (2010). Molecular characterization of foot and mouth diseases viruses collected from Sudan. Trans. Emerg. Dis. 57:305-314.

7. Latif, A.A. (1994). Economic losses in exotic breeds of cattle due to Theileriosis in Sudan. Mannaa and Kheir (eds). Proceedings of tropical theileriosis orkshop, 4-5 May 1994,Khartoum,Sudan.pp 1-11. 